\title{
Less Complexity in Hemodialysis Machines Reduces Time and Physical Load for Operator Actions
}

\author{
Uwe Gründler' \\ Eva Ekesbo ${ }^{2}$ \\ Martin Löwe' \\ Adelheid Gauly (iD ${ }^{3}$ \\ 'REFA Consulting AG, Dortmund, \\ Germany; ${ }^{2}$ BetaHälsan $A B$, Lund, \\ Sweden; ${ }^{3}$ Fresenius Medical Care, Global \\ Medical Office, Bad Homburg, Germany
}

Correspondence: Adelheid Gauly Fresenius Medical Care Deutschland GMBH, Global Medical Office, 3 ElseKröner-Strasse, Bad Homburg 61352, Germany

Tel +4961726092260

Email adelheid.gauly@fmc-ag.com
Purpose: Innovative hemodialysis systems are designed to ensure user safety and reduce operational time to allow health-care personnel to focus on patient care. The 6008 CareSystem has been developed to simplify the extracorporeal circuit of the system through a disposable cassette, automate operation steps, and facilitate handling in comparison to its predecessor - the 5008 CorDiax. The present investigations were performed with the aim of evaluating usability, safety, and ergonomic aspects of the new therapy system.

Methods: A time-motion study compared these two hemodialysis systems with video and time recording of handling steps required to prepare, operate, and dismantle a dialysis machine. The ergonomic burden on hands and finger joints was evaluated in a second study, again by video-recording the simulated operation of both dialysis systems.

Results: The number of handling steps required for the 6008 CareSystem and critical contact points were reduced by $26 \%$ in comparison to the 5008 CorDiax for patients with arteriovenous fistula used for vascular access and by $22 \%$ for those with a catheter used for vascular access. Total process time was reduced by 2.83 and 2.57 minutes using fistulae and catheters for vascular access, respectively. The number of hand grips and finger and thumb presses was reduced by approximately $50 \%$ and required less strength to execute.

Conclusion: The most recent hemodialysis system confirmed its ease of use and user safety through fewer handling steps and less physical burden on the user. Shorter operational time should enable more patient-focused care.

Keywords: ergonomics, usability, hemodialysis equipment, safety

\section{Introduction}

The number of patients depending on kidney-replacement therapies worldwide is rising steadily. Increasingly complex patients are more demanding for physicians and nurses, requiring more time to dedicate to each patient. Alongside this are the often-raised problems of understaffing in dialysis centers, an increasing patient: nurse ratio, and overall time and cost pressures. ${ }^{1-3}$ This situation demands facilitation of processes in routine dialysis delivery, including dialysis machines that should be simple and safe to handle to leave more time for direct patient care.

In hemodialysis (HD) centers, nurses usually take care of several patients and dialysis machines during a shift. ${ }^{4}$ This includes numerous handling steps at the machine following standardized processes. In addition, the demand by the individual patient and further organizational tasks, eg, documentation, requires the nurses' attention.

HD systems should be optimized by reducing the number of handling steps to lower complexity and possibilities of error, reducing the number of steps posing risk 
of cross-contamination, and automate certain steps to reduce workload and operational time in setting up and dismantling the machine. Since the work environment is an important factor that contributes to nurse turnover, ${ }^{5}$ easyto-learn equipment and processes are gaining importance also in the context of managing increasing staff shortages. In view of safety, ${ }^{6}$ minimal infection risk, unambiguous handling procedures, and safety from health-associated consequences of repeating standardized movements should be considered. Simplified handling can be particularly supported by reducing the number of disposables needed, which in addition may facilitate the organization of material supply in the dialysis center. For the patient, safety is associated with minimal risk of contamination, hemodynamically stable treatments, and absence of other undesired events.

The interaction of users - whether clinical staff or laypersons - with a medical device is a subject of the science of human-factor engineering, often synonymously called "usability" or "ergonomics."7,8 This discipline aims toward system designs that are easy to learn, with unambiguous interaction between user and machine, understandable instructions of use, and clear information and help in cases of malfunction and alarms. The ultimate goal is patient safety and user satisfaction, with potential effects on health-care costs and increased acceptance by all users.

In the following, the development path of recent HD systems in view of human factors and ergonomics are elaborated upon as a case study on the 5008 CorDiax and the 6008 CareSystem (both Fresenius Medical Care, Bad Homburg, Germany). The 5008 family of HD systems was released in 2005 as an innovative HD machine incorporating demands for an ergonomic, user-friendly, and safe device. ${ }^{9}$ The extracorporeal system consists of several products, which may be subject to revision. Further addressed is the setup and dismantling of the HD machine, which includes numerous steps, some of them involving contamination risk. Since the manipulation of the dialysis machine and disposables includes repetitive and sometimes forceful handling steps, a major developmental goal of the 6008 CareSystem was to further optimize ergonomic aspects and facilitate usability considering the aforementioned points.

Usability is an objective of the development process of a medical device, but needs attention also over its entire life cycle of postmarketing surveillance. ${ }^{10}$ Several usability and ergonomic tests with the new 6008 CareSystem to underpin advances in ease of handling, operation time, user safety, and the evolution of ergonomic properties are presented.

\section{Methods}

\section{Devices}

The major innovations in the 6008 CareSystem in comparison to the 5008 CorDiax are the automation of certain steps in the preparation of the system and the use of a closed, disposable, all-in-one cassette (6008 CareSet) that automatically connects with the integrated infusion port to perform online priming, substitution, and reinfusion. Switch of reinfusion during hemodiafiltration (HDF) treatment between post- and predilution modes, ie, between infusion after and before the dialyzer (eg, due to increased blood viscosity), is possible without manual interaction with the extracorporeal system. This allows continuation of the treatment without interruption or premature termination. Also, treatments in single-needle and double-needle mode can be performed with the same cassette. Therefore, only one disposable, ie, the cassette, connected to the blood lines is necessary for treatment, in contrast to three lines to be assembled with preceding generations of HD machines (Figures 1 and 2).

\section{Time-Motion Study}

This study was performed to compare all handling steps during use of the 5008 CorDiax and the 6008 CareSystem for online HDF, and to quantify handling steps as a whole, contact points that could possibly lead to transmission of infections, and time needed for these handling steps.

The study was undertaken by REFA Consulting (Dortmund, Germany), an institute specialized in the analysis of work processes, at Maingau Hospital, Frankfurt, Germany. All treatments were performed by experienced nurses of the dialysis center using both HD systems in a clinical setting. Eleven HDF treatments with the 6008 CareSystem were recorded and three with the 5008 CorDiax. A further two treatments with the latter system were simulated in the laboratory. All treatments were video-recorded to count and derive time intervals for defined handling steps. Only the time that the operator had to spend on actual handling was counted, not any waiting time, since this can be used to set up further dialysis machines. A handling step was defined as a risk step or critical contact point, when the normal handling procedure involved opening a blood-bearing connection during a manipulation step. 


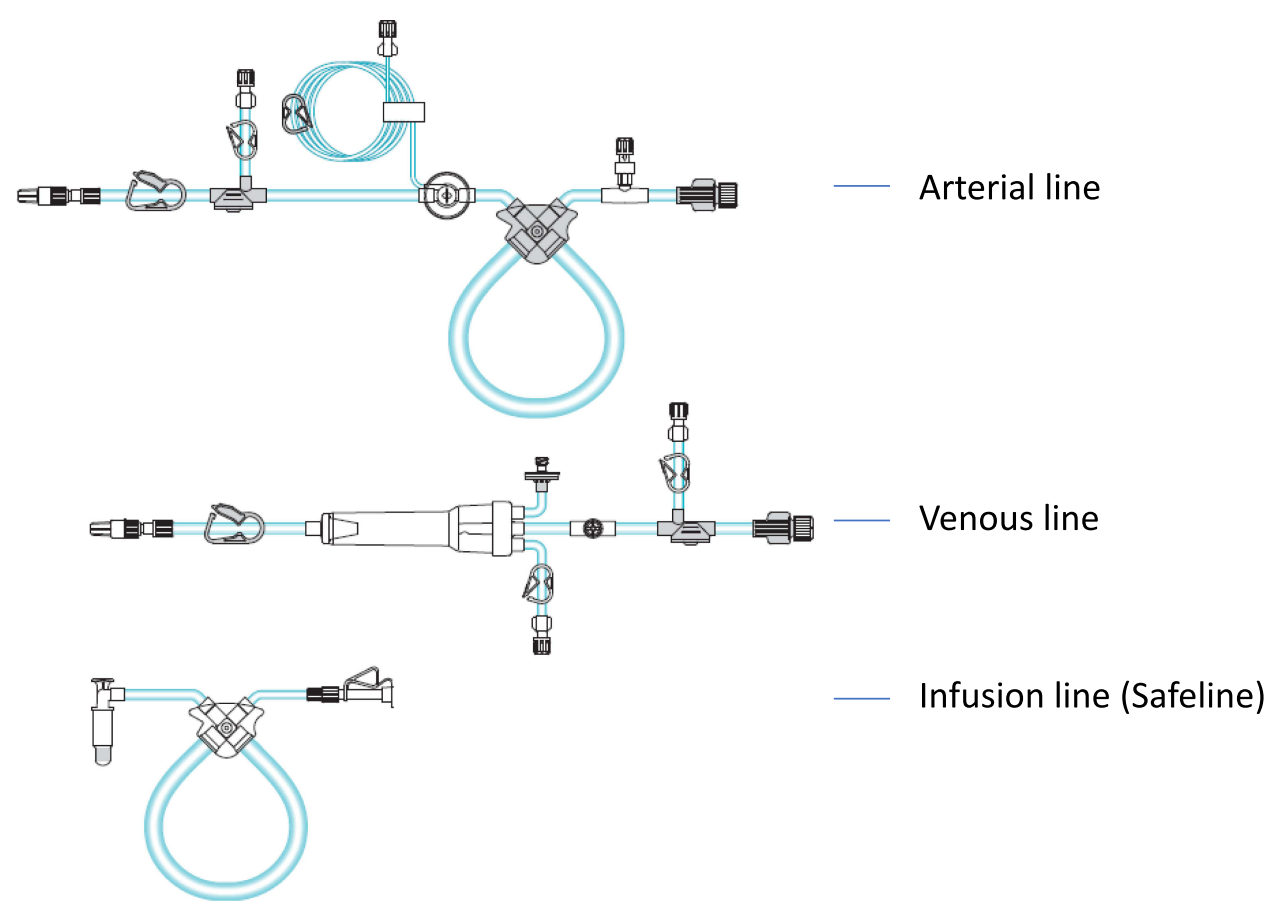

Figure I Blood lines for the extracorporeal circuit in the 5008 CorDiax HD system and safeline needed for online hemodiafiltration treatments and priming (filling and reinfusion).

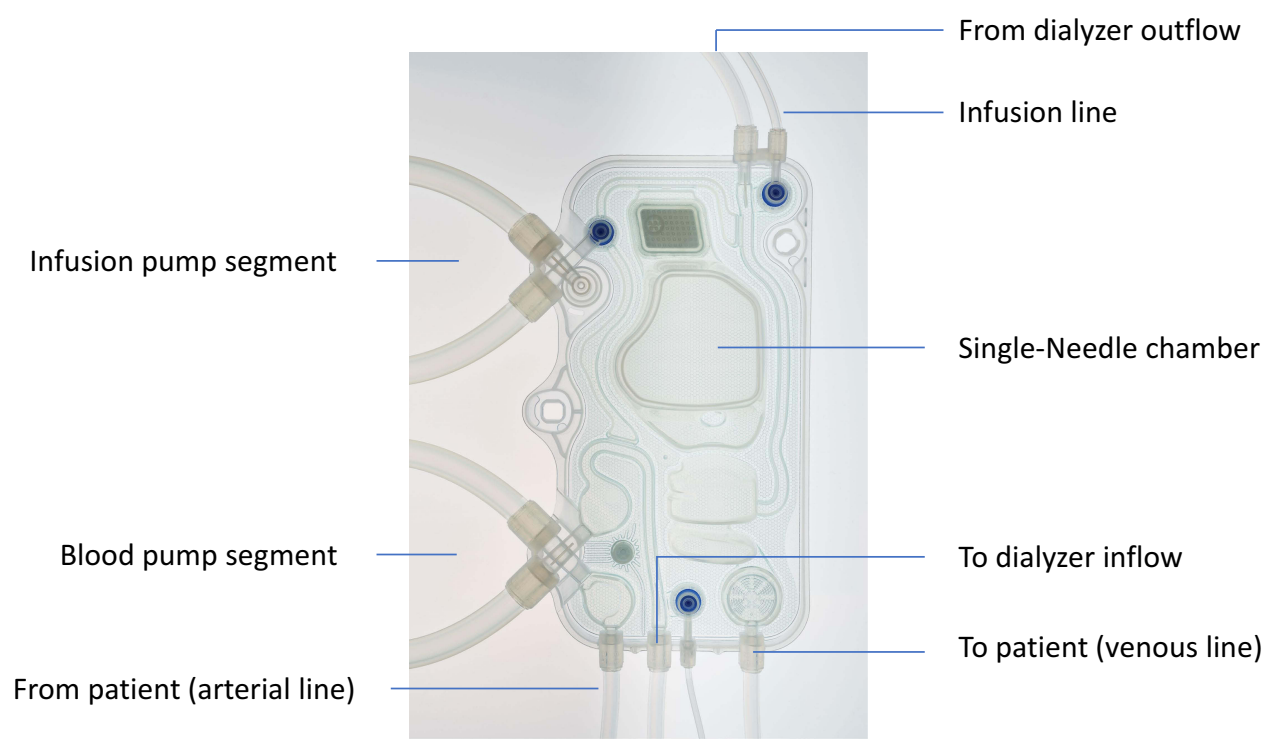

Figure 2 Extracorporeal circuit for the 6008 CareSystem as all-in-one cassette (6008 CareSet).

Patients' consent for video-recording was collected before the study. Analysis of time data was performed with OrtimZeit software (DMC Ortim, Kiel, Germany).

\section{Ergonomic Study}

An ergonomic simulation study was performed by BetaHälsan AB (Lund, Sweden), a company specialized in work-related safety and health, to compare the number and type of hand grips and finger actions necessary to prepare and dismantle both dialysis systems for online HDF treatment.

Treatment preparation and termination with both dialysis machines were simulated once each by an experienced nurse familiar with both systems: priming, connecting the patient, disconnecting the patient, and removing the bloodlines from the machine. The complete procedure was video-recorded to allow counting of each 
type of grip with fingers, hands, and wrists. The force needed to execute each of these steps was estimated and categorized as no force/holding, light force, or strong force. For grips and movements, where an estimation of force was not directly possible, and in order to quantify tasks that needed strong force, a pinch gauge was used to apply the same force as during machine manipulation for the step. Assessment of hand activity and level of effort while performing the tasks investigated was done using the hand activity level-threshold limit value (HAL TLV). ${ }^{11,12}$ This estimates the force (normalized peak force) applied using the Borg CR10 scale $^{13}(0-10)$ and HAL (0-10) taking frequency of hand activity into account. $^{11}$ The former is plotted on the $y$-axis and the latter on the $x$-axis of the HAL TLV graph. The mean value of the estimated force required for all evaluated tasks to operate the two HD systems was the basis for measurement of the two systems in the HAL TLV graph. HAL-TLV limits as displayed in Figure 2 have been validated in a cohort of service and industrial workers demonstrating increased risk of development of carpal tunnel syndrome for those classified between the action limit and the TLV. ${ }^{14}$
Special focus was put on pressing with the thumbs, which was analyzed separately. Each handling step was analyzed individually, with one treatment per system being simulated.

\section{Analysis}

Both studies are analyzed descriptively only.

\section{Results \\ Handling of the 6008 CareSystem}

With the 6008 CareSystem employing a cassette system a couple of handling steps necessary in HD systems using conventional bloodline systems become obsolete: the connection of an infusion line, arterial disconnection, and manual start of emptying the extracorporeal system (Figure 3). The 6008 CareSystem allows closed-circuit reinfusion after double-needle treatment without disconnecting the arterial line from the arterial needle, which further reduces operator-handling steps and promotes aseptic practice.

Due to the design changes, the number of handling steps to set up, operate, and dismantle the HD system was reduced from 122 with the 5008 CorDiax to 92 with the 6008
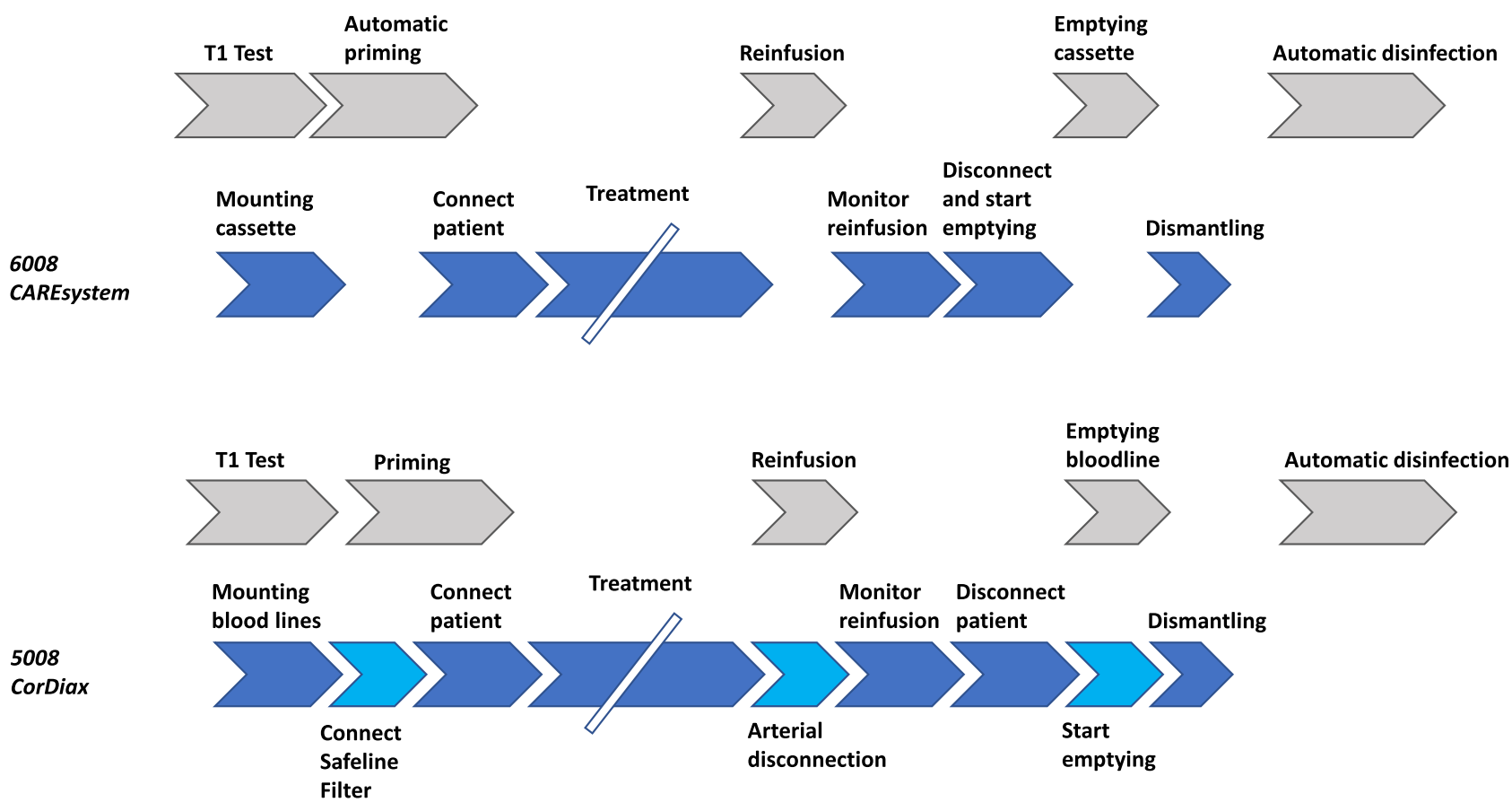

Process steps requiring an operator

Differential process steps 5008 CorDiax vs 6008 CAREsystem
Process steps of the device without operator action

Figure 3 Operator steps critical to successful hemodialysis-machine use. 
CareSystem in patients treated via a fistula for vascular access and from 145 to 113 for patients receiving HD via a catheter. The number of critical contact points with the 6008 CareSystem was reduced from 31 to 23 using fistula as vascular access and from 36 to 28 using catheter as vascular access compared to the 5008 CorDiax (Table 1). This reduction results from the switch from an infusion line to an integrated infusion port in the cassette and the lack of a venous chamber in the 6008 CareSet, with consequently fewer positions at risk of microbial contamination.

\section{Time-Motion Study}

This simplified handling of the dialysis machine led to a reduction in total process time resulting from device-related steps (Figure 3), with time savings per treatment of 2.83 minutes in patients with fistula as vascular access and 2.59 minutes in those using catheter as vascular access. Major time savings were realized during setup - 3.70 minutes with the 5008 CorDiax and 1.94 minutes with the 6008 CareSystem -

Table I Handling steps and critical contact points per treatment necessary to prepare, operate, and dismantle the two hemodialysis systems

\begin{tabular}{|l|c|c|}
\hline & $\begin{array}{c}5008 \\
\text { CorDiax }\end{array}$ & $\begin{array}{c}6008 \\
\text { CareSystem }\end{array}$ \\
\hline Steps, $\mathbf{n}$ & 122 & 92 \\
\hline Patients with fistula as vascular access & 145 & 113 \\
Patients with catheter as vascular access & & \\
\hline Critical contact points, $\mathbf{n}$ & 31 & 23 \\
\hline Patients with fistula as vascular access & 36 & 28 \\
\hline Patients with catheter as vascular access &
\end{tabular}

as a result of fewer steps and number of interactions of the user with the device needed with the latter system (Table 2).

\section{Ergonomic Study}

Grips and movements with hands and fingers were counted through analysis of the video recording of simulated preparation and dismantling of the machines for HDF treatment. With the 5008 CorDiax, 349 and with the 6008 CareSystem 174 hand grips and movements with the hands, fingers, or thumbs were recorded (Table 3). The number of thumb pressings needed with the 5008 CorDiax was 277 compared to 112 with the 6008 CareSystem. With the 5008 CorDiax, 9\% of left and $11 \%$ of right-thumb pressings needed strong force, while all those during operation of the 6008 CareSystem were able to be executed with light force (Table 3). With the 5008 CorDiax, pressing the bloodlines into the optical detector and blood pump were tasks that required strong force.

In the HAL-TLV graph the normalized peak force (Borg CR10) was estimated for the 5008 CorDiax at 2-4 with an average of 3 , and the hand-activity continuum was estimated at 5-6 (6 is steady motion/easier exertion, infrequent pauses). This resulted in scoring between the action limit and the threshold limit value. For the 6008 CareSystem, normalized peak force was estimated at 0.5-2 with an average of 1 , and on the hand activity continuum it was estimated at 5-6 but exerted for a shorter time/day, thus scoring below the action limit (Figure 4).

Likewise, the quality of grips was different between the two systems. With the 6008 system, often bigger grips and spreading the load to more joints are executed, and applying no force/holding is more frequent than light or strong grips.

Table 2 Time needed for handling steps for 5008 CorDiax and 6008 CareSystem

\begin{tabular}{|l|c|c|c|c|c|c|c|}
\hline & \multicolumn{3}{|c|}{$\mathbf{5 0 0 8}$ CorDiax } & \multicolumn{3}{|c|}{$\mathbf{6 0 0 8}$ CareSystem } & \\
\cline { 2 - 8 } & $\mathbf{n}$ & $\begin{array}{c}\text { Mean } \\
\text { (minutes) }\end{array}$ & $\begin{array}{c}\text { SD } \\
\text { (minutes) }\end{array}$ & $\mathbf{n}$ & $\begin{array}{c}\text { Mean } \\
\text { (minutes) }\end{array}$ & $\begin{array}{c}\text { SD } \\
\text { (minutes) }\end{array}$ & $\begin{array}{c}\text { Time savings } \\
\text { (minutes) }\end{array}$ \\
\hline Machine preparation & 5 & 3.70 & 0.75 & 7 & 1.94 & 0.27 & 1.76 \\
Puncturing of a fistula patient using a connection set & 3 & 0.94 & 0.02 & 3 & 0.62 & 0.17 & 0.32 \\
Connection of a patient using a catheter-connection set & 2 & 0.68 & 0.00 & 5 & 0.60 & 0.16 & 0.08 \\
Reinfusion (assumed with simultaneous AV reinfusion) & 4 & 0.61 & 0.16 & 4 & 0.12 & 0.03 & 0.49 \\
Dismantling of 6008 & 4 & 1.23 & 0.21 & 4 & 0.98 & 0.16 & 0.26 \\
\hline Sum fistula & & 6.48 & & & 3.65 & & \\
Sum catheter & & 6.23 & & & 3.64 & & 2.83 \\
\hline
\end{tabular}

Abbreviation: AV, arteriovenous. 
Table 3 Hand activity derived from ergonomic video analysis of each simulation study with the two hemodialysis systems

\begin{tabular}{|l|c|c|}
\hline & $\begin{array}{c}\mathbf{5 0 0 8} \\
\text { CorDiax }\end{array}$ & $\begin{array}{c}\mathbf{6 0 0 8} \\
\text { CareSystem }\end{array}$ \\
\hline $\begin{array}{l}\text { Total grips/movements with } \\
\text { hand, fingers, and thumbs } \\
\text { Left }\end{array}$ & 175 & 86 \\
Right & 174 & 88 \\
\hline $\begin{array}{l}\text { Total thumb pressings, } \mathbf{n} \\
\text { Left (with strong pressure) }\end{array}$ & $119(13)$ & $46(0)$ \\
Right (with strong pressure) & $158(14)$ & $66(0)$ \\
\hline
\end{tabular}

\section{Discussion}

The present investigations on the usability of the newest generation of HD machines demonstrate improvements on handling and ergonomics. These were realized in the 6008 CareSystem by a single cassette substituting the conventional arterial and venous bloodlines, and additionally the disposable for fluid infusion. Through automation of certain processes in the dialysis machine, the number of handling steps and touch points with potential contamination risks was reduced by $26 \%$ and $22 \%$ using catheters and fistulae for vascular access, respectively. As a consequence, operator time was reduced as well. This should facilitate the overall operation of the machine and improve user-related safety. Further, through design of the machine and the disposable, specific handling steps could be omitted or modified to reduce physical burden on the operator's hands and joints. Easier-to-use medical devices can improve from the nurse's perspective technology acceptance, motivation, and job satisfaction. ${ }^{7}$ For the dialysis center, the disposable cassette system has impact on organizational and supply aspects, as only one instead of two systems (for single- and double-needle treatment) are required to be kept in stock.

We considered net operation time in a real patient setting, which was reduced with the 6008 CareSystem by approximately 2.5 minutes/treatment in comparison to the 5008 CorDiax. In a simulation study on preparation and dismantling five machines in parallel — a realistic situation in a dialysis center - a notable reduction in overall operation time of approximately 5 minutes per machine and treatment has been achieved. ${ }^{15}$ This assessment also took time for automated processes into account, where no active intervention of the user takes place.

Saving of operation time with a dialysis machine allows easier control of several machines in parallel and to dedicate the time saved to patients with diverse medical conditions

HAL TLV Scoring Graph

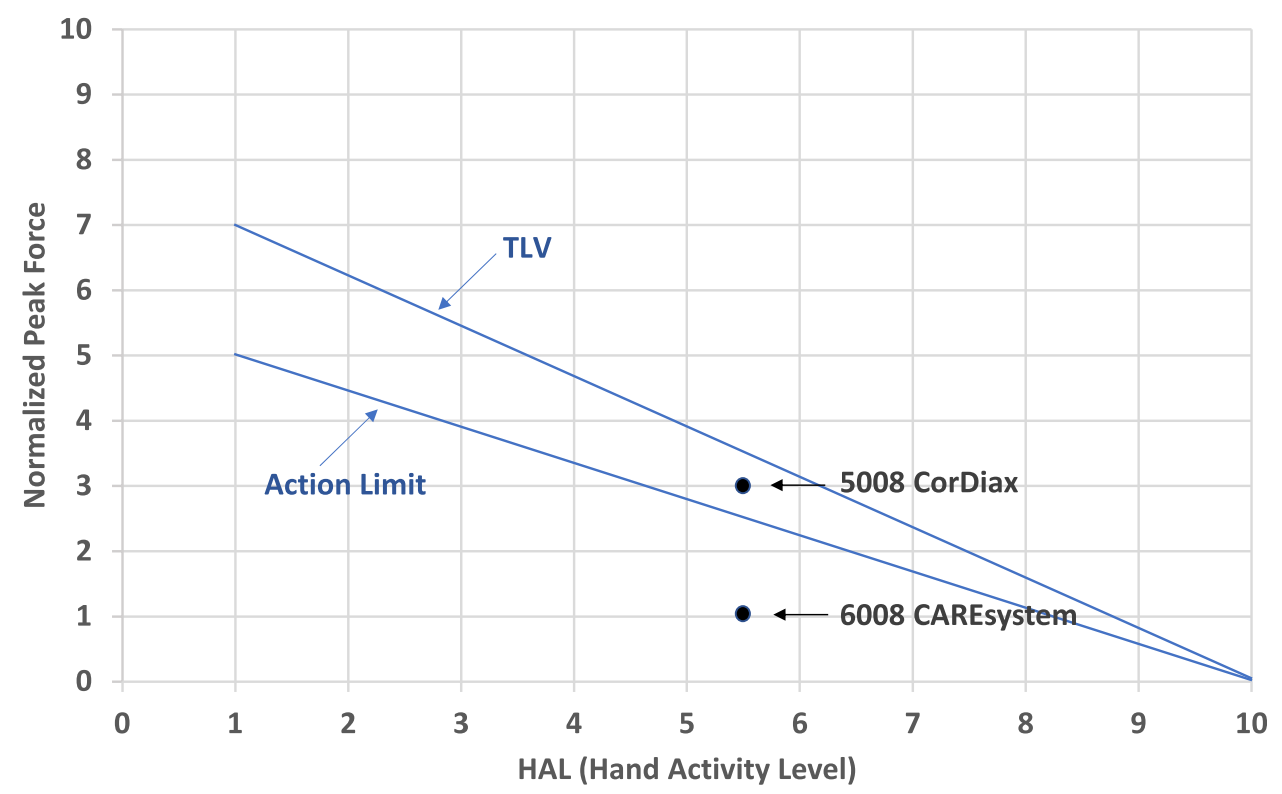

Figure 4 Classification of the HD systems on an HAL TLV graph, with threshold -limit value (TLV) and action limit as per Bernard. ${ }^{\prime \prime}$ Reproduced from Bernard TE. ACGIH TLV for Hand Activity. American Conference of Governmental Industrial Hygienists (ACGIH), 2002. From ACGIH ${ }^{\circledR}$, Documentation of the Threshold Limit Values and Biological Exposure Indices, 9th Edition. (C) 2021. Statement of Position Regarding the TLVs ${ }^{\circledR}$ and BEls ${ }^{\circledR}$. Available from: https://www.acgih.org/science/tlv-bei-guidelines/policiesprocedures-presentations/tlv-bei-position-statement/. Policy Statement on the Uses of TLVs ${ }^{\circledR}$ and BEls ${ }^{\circledR}$. Available from: https://www.acgih.org/science/tlv-bei-guidelines/ policies-procedures-presentations/tlv-bei-policy-statement/. " 
requiring special attention and flexibility to provide the appropriate extent of specific care. ${ }^{16}$ The resulting quality of physician and nursing care are major priorities from the patients' perspective. ${ }^{17}$ Nurses working in a dialysis center identify many factors as potential stressors, among which are situations associated with lack of time and understaffing. ${ }^{18,19}$ Therefore, the risk of staff burnout and connection to patient satisfaction must be kept in mind. ${ }^{20}$

A long-term safety aspect is the physical demand to hands, joints, and fingers of users operating the device and disposables. Through considering ergonomic aspects in the design of each single part and the quality and quantity of hand and finger activities required, the user is at less physical risk. In view of preparing several dialysis machines per shift and being in service up to 5 days/ week this aspect is particularly relevant for the nursing staff. With the design improvements in the 6008 CareSystem, hand activity and level of effort were able to be categorized below the action limit of the HAL TLV. ${ }^{11}$ This could be beneficial, as repeated hand manipulations above the action limit and TLV may have long-term consequences, such as overloading the joints, which causes pain, and an elevated risk of carpal tunnel syndrome. ${ }^{21}$ Physical workload and work-related burden on hands and repeated movements, including pinches and grips, may predispose thumbs and fingers to developing osteoarthritis, particularly in women and with increasing age. ${ }^{22-24}$ Currently, more and more health-care systems not only encourage but incentivize an increased proportion of patients on home $\mathrm{HD},{ }^{25}$ and patients also consider home and self-care options for their kidney-replacement therapy. ${ }^{26}$ Therefore, all aspects of reducing handling effort and the number of contamination risk-related steps are a basis for considering HD-system use at home. The learnability of the system, usability of the technology by the patient or nonprofessional caregiver, and remote monitoring options are considered important to safely manage dialysis at home, ${ }^{27}$ where ease of use is important to minimize risk to the patient or of caregiver burnout. ${ }^{28}$

Besides improved safety aspects engineered specifically for the evolution from the 5008 family to the 6008 CareSystem, other safety features to ensure patient safety have been maintained or introduced, including venous access monitoring to detect needle dislodgement, bloodtemperature and blood-volume monitoring, ${ }^{29,30}$ and sodium balancing, ${ }^{31}$ to improve treatment quality and safety. ${ }^{32}$

Both studies have limitations, were monocentric, and the monitored operations were executed only by few, albeit experienced dialysis nurses. For generalizability, further usability studies with larger samples executed in more diverse settings of dialysis centers should be considered. The user perspective could be reinforced by including usersatisfaction surveys and investigating how the evolution of the HD systems enhances patient and user safety. A bias in the results due to the studies' observational nature cannot be fully excluded, but its potential impact was contained through comparing two systems under the same conditions.

\section{Conclusion}

For the most current HD system, it was possible to illustrate the intended progress of its user-friendliness and potential safety through fewer handling steps overall, fewer handling steps with potential risk of contamination, and handling steps with less physical stress for users to hands and joints. Saving operational time enables more patient-focused care to support nursing staff in the center and to enable the system to be used in the home setting. Further field studies on the impact of improvements in HD-machine handling on usability, safety, patient outcomes, and nurse satisfaction are warranted.

\section{Ethics}

The paper is exempt from ethics committee approval, because these usability studies were not clinical investigations on the performance and safety of a medical device or conducted on patients, and did not collect any health-related data. In the absence of diagnostic or therapeutic interventions, consultation with an institutional review board was not required.

Patients' informed consent for video and audio recording of their treatments was collected in writing before start of the study.

\section{Acknowledgments}

The staff at the Maingau Hospital, Frankfurt are gratefully acknowledged for their permission to do the time-motion study at their institution.

\section{Funding}

Both studies were funded by Fresenius Medical Care. The design of the studies and collection, analysis, and interpretation of data was done by REFA Consulting and BetaHälsan independently of the funding source. Drafting, review, approval, and decision to submit the article for publication was done jointly by REFA Consulting, BetaHälsan, and Fresenius Medical Care. 


\section{Disclosure}

UG and ML are full-time employees of REFA Consulting, EE is a physiotherapist, ergonomist, and owner of BetaHälsan, and AG is a full-time employee of Fresenius Medical Care. The authors report no other conflicts of interest in this work.

\section{References}

1. Nobahar M, Tamadon MR. Barriers to and facilitators of care for hemodialysis patients; a qualitative study. $J$ Renal Inj Prev. 2016;5:39-44. doi:10.15171/jrip.2016.09

2. Vanholder R, Lameire N, Annemans L, et al. Cost of renal replacement: how to help as many as possible while keeping expenses reasonable? Nephrol Dial Transplant. 2016;31(8):1251-1261. doi:10.1093/ndt/gfv233

3. Osman MA, Alrukhaimi M, Ashuntantang GE, et al. Global nephrology workforce: gaps and opportunities toward a sustainable kidney care system. Kidney Int Suppl. 2018;8:52-63. doi:10.1016/j.kisu.2017.10.009

4. Thomas-Hawkins C, Flynn L, Clarke SP. Relationships between registered nurse staffing, processes of nursing care, and nurse-reported patient outcomes in chronic hemodialysis units. Nephrol Nurs J. 2008;35:123-130.

5. Gardner JK, Thomas-Hawkins C, Fogg L, et al. The relationships between nurses' perceptions of the hemodialysis unit work environment and nurse turnover, patient satisfaction, and hospitalizations. Nephrol Nurs J. 2007;34:271-281.

6. Ward RA, Ronco C. Dialyzer and machine technologies: application of recent advances to clinical practice. Blood Purif. 2006;24(1):6-10. doi:10.1159/000089429

7. Carayon P, Xie A, Kianfar S. Human factors and ergonomics as a patient safety practice. BMJ Qual Saf. 2014;23(3):196-205. doi:10.1136/bmjqs-2013-001812

8. Applying Human Factors and Usability Engineering to Medical Devices. Guidance for Industry and Food Administration Staff. USA: Food and Drug Administration; 2016.

9. Jonas J. Telephone interview with Fresenius Medical Care project leader Mr. Jonas: launch of 5008 Therapy System. EDTNA/ERCA J. 2006;32:68.

10. Regulation (EU) $2017 / 745$ on Medical Devices. European Parliament and the Council of the European Union; 2017.

11. Bernard TE ACGIH TLV for Hand Activity. American Conference of Governmental Industrial Hygienists (ACGIH), 2002. Statement of Position Regarding the TLVs ${ }^{\circledR}$ and BEIs ${ }^{\circledR}$ and Policy Statement on the Uses of TLVs ${ }^{\mathbb{B}}$ and BEIs ${ }^{\mathbb{B}}$ are available from: https://www.acgih. org/science/tlv-bei-guidelines/policies-procedures-presentations/tlvbei-position-statement/ and https://www.acgih.org/science/tlv-beiguidelines/policies-procedures-presentations/tlv-bei-policy-statement/ . Accessed November 12, 2021.

12. Wurzelbacher S, Burt S, Crombie K, et al. A comparison of assessment methods of hand activity and force for use in calculating the ACGIH(R) hand activity level (HAL) TLV(R). J Occup Environ Hyg. 2010;7:407-416. doi:10.1080/15459624.2010.481171

13. Borg G. Psychophysical scaling with applications in physical work and the perception of exertion. Scand $J$ Work Environ Health. 1990;16(Suppl 1:):55-58. doi:10.5271/sjweh.1815

14. Bonfiglioli R, Mattioli S, Armstrong TJ, et al. Validation of the ACGIH TLV for hand activity level in the OCTOPUS cohort: a two-year longitudinal study of carpal tunnel syndrome. Scand J Work Environ Health. 2013;39:155-163. doi:10.5271/sjweh.3312

15. Volf P, Kneppo P, Kudrna P, et al. Increased efficiency of dialysis delivery through reduced active machine handling time and process steps for nurses with an advanced dialysis system. Kidney Int Rep. 2020;5:S297. doi:10.1016/j.ekir.2020.02.773
16. de Kleijn R, Hagen C, Uyl-de Groot C, et al. Prediction of care burden of patients undergoing haemodialysis: development of a measuring tool. J Ren Care. 2015;41:119-125. doi:10.1111/jorc.12109

17. Rubin HR, Jenckes M, Fink NE, et al. Patient's view of dialysis care: development of a taxonomy and rating of importance of different aspects of care. CHOICE study. Choices for Healthy Outcomes in Caring for ESRD. Am J Kidney Dis. 1997;30:793-801. doi:10.1016/ S0272-6386(97)90084-6

18. Dermody K, Bennett PN. Nurse stress in hospital and satellite haemodialysis units. J Ren Care. 2008;34:28-32. doi:10.1111/j.17556686.2008.00007.x

19. Moisoglou I, Yfantis A, Tsiouma E, et al. The work environment of haemodialysis nurses and its mediating role in burnout. J Ren Care. 2020. doi:10.1111/jorc. 12353

20. Argentero P, Dell'Olivo B, Ferretti MS. Staff Burnout and Patient Satisfaction With the Quality of Dialysis Care. Am J Kidney Dis. 2008;51:80-92. doi:10.1053/j.ajkd.2007.09.011

21. Kozak A, Schedlbauer G, Wirth T, et al. Association between work-related biomechanical risk factors and the occurrence of carpal tunnel syndrome: an overview of systematic reviews and a meta-analysis of current research. BMC Musculoskelet Disord. 2015;16(1):231. doi:10.1186/s12891-015-0685-0

22. Haara MM, Manninen P, Kröger H, et al. Osteoarthritis of finger joints in Finns aged 30 or over: prevalence, determinants, and association with mortality. Ann Rheum Dis. 2003;62:151-158. doi:10.1136/ard.62.2.151

23. Winzeler S, Rosenstein BD. Occupational injury and illness of the thumb. Causes and solutions. AAOHN J. 1996;44:487-492. doi: $10.1177 / 216507999604401005$

24. Kalichman L, Hernández-Molina G. Hand osteoarthritis: an epidemiological perspective. Semin Arthritis Rheum. 2010;39:465-476. doi:10.1016/j.semarthrit.2009.03.001

25. Abra G, Schiller B. Public policy and programs - Missing links in growing home dialysis in the United States. Semin Dial. 2020;33:75-82. doi:10.1111/sdi.12850

26. Goovaerts T, Jadoul M, Goffin E. Influence of a pre-dialysis education programme (PDEP) on the mode of renal replacement therapy. Nephrol Dial Transplant. 2005;20:1842-1847. doi:10.1093/ndt/gfh905

27. Rajkomar A, Farrington K, Mayer A, et al. Patients' and carers' experiences of interacting with home haemodialysis technology: implications for quality and safety. BMC Nephrol. 2014;15(1):195. doi:10.1186/1471-2369-15-195

28. Shah N, Reintjes F, Courtney M, et al. Quality Assurance Audit of Technique Failure and 90-Day Mortality after Program Discharge in a Canadian Home Hemodialysis Program. Clin J Am Soc Nephrol. 2017;12:1259-1264. doi:10.2215/CJN.00140117

29. Maggiore Q, Pizzarelli F, Santoro A, et al. The effects of control of thermal balance on vascular stability in hemodialysis patients: results of the European randomized clinical trial. Am J Kidney Dis. 2002;40:280-290. doi:10.1053/ajkd.2002.34506

30. Gabrielli D, Krystal B, Katzarski K, et al. Improved intradialytic stability during haemodialysis with blood volume-controlled ultrafiltration. J Nephrol. 2009;22:232-240.

31. Ságová M, Wojke R, Maierhofer A, et al. Automated individualization of dialysate sodium concentration reduces intradialytic plasma sodium changes in hemodialysis. Artif Organs. 2019;43 (10):1002-1013. doi:10.1111/aor.13463

32. Doria M, Genovesi S, Biagi F, et al. The dialysis staff workload and the blood volume tracking system during the hemodialysis sessions of hypotension-prone patients. Int J Artif Organs. 2014;37:292-298. doi:10.5301/ijao.5000318 


\section{Publish your work in this journal}

Medical Devices: Evidence and Research is an international, peerreviewed, open access journal that focuses on the evidence, technology, research, and expert opinion supporting the use and application of medical devices in the diagnosis, monitoring, treatment and management of clinical conditions and physiological processes. The identification of novel devices and optimal use of existing devices which will lead to improved clinical outcomes and more effective patient management and safety is a key feature of the journal. The manuscript management system is completely online and includes a very quick and fair peer-review system. Visit http:// www.dovepress.com/testimonials.php to read real quotes from published authors. 